\title{
Nitric Oxide Level Estimation in Patients of Oral Lichen Planus in Kashmiri Population - An Original Research
}

\author{
Altaf Hussain Chalkoo, Prenika Sharma, Nusrat Nazir Makroo \\ Department of Oral Medicine and Radiology, Government Dental College and Hospital, Srinagar, Jammu and Kashmir, India
}

Email for correspondence: drnusratnaziromar@gmail.com

\begin{abstract}
Background: The role of stress oxidative indices has been introduced in many autoimmune and inflammatory diseases such as atopic dermatitis, psoriasis vulgaris, vitiligo, and dermal lichen planus. Oxidative stress and antioxidant defense mechanism may play an important role in the pathology of oral lichen planus (OLP). Aims and Objectives: This study aims to evaluate the levels of nitric oxide (NO) in serum of patients with OLP and to compare the levels with the controls. Materials and Methods: The study included 30 cases of OLP patients which formed the study group and 30 cases of healthy individuals, which formed the controls. Results: The levels of NO were significantly higher in serum of cases with lichen planus than in normal. Conclusion: Serum NO was found to be higher in OLP patients which suggested that higher serum levels of NO in patients with OLP might activate the process of lymphocytes and cellular immunity system, hence, possibly endorsing the effect of serum NO in pathogenesis of lichen planus.
\end{abstract}

Key words: Nitric oxide, oral lichen planus, oxidative stress

\section{INTRODUCTION}

Oral lichen planus (OLP) is a non-infectious chronic inflammatory condition that involves the oral mucosal stratified squamous epithelium and the underlying lamina propria, which may be accompanied by skin lesions. ${ }^{[1]}$ The exact pathogenesis is unknown, but cell-mediated immunity and humoral immunity have been implicated. Activation of the cell-mediated immune response destined toward keratinocyte apoptosis is the prime event in the pathogenesis of LP. ${ }^{[2]}$ Recent studies have reported an increased oxidative stress and lipid peroxidation in patients with lichen planus. ${ }^{[3]}$ Overproduction of reactive oxygen species

\section{Quick Response Code Article Info:}

\begin{tabular}{l} 
doi: 10.5866/2019.11.10013 \\
$\begin{array}{l}\text { Received: 06-01-2019 } \\
\text { Revised: 08-02-2019 } \\
\text { Accepted: 07-03-2019 } \\
\text { Available Online: 01-04-2019, (www. } \\
\text { nacd.in)@ NAD, 2019 - All rights } \\
\text { reserved }\end{array}$ \\
\hline
\end{tabular}

can be a crucial mediator of damage to the cell structures including lipids, membrane, proteins, and DNA. ${ }^{[4]}$ The role of stress oxidative indices has been introduced in many autoimmune and inflammatory diseases such as atopic dermatitis, psoriasis vulgaris, vitiligo, and dermal lichen planus. ${ }^{[5-8]}$

Since the etiology of lichen planus is still unidentified, the treatment of the disease would be a symptomatic approach. Most of the previous studies in this field have been carried out on the dermal and genital lichen planus; therefore, the present study was aimed to evaluate the oxidative stress with the nitric oxide (NO) index in a sample of Kashmiri population with OLP to detect the etiopathogenesis of the disease and to give some intimation to find a relevant treatment.

\section{MATERIALS AND METHODS}

The present study was conducted in the Department of Oral Medicine and Radiology, Government Dental College, Srinagar. Patients were clinically and histopathologically diagnosed cases of OLP. The present study included 30 cases 
of OLP, which included fresh cases visiting outpatient department and few were follow-up cases [Figure 1 and Tables 1 and 2]. Patient treated with immunosuppressive agents, steroids, nonsteroidal anti-inflammatory drugs, topical medications during the past 4 weeks, systemic diseases, and malignancies were excluded. The control subjects were 30 healthy individuals from the OPD matched for age and gender. A written informed consent was obtained from all patients and control subjects. The study was approved by the internal Research Ethical Committee of our Institution.

For collecting serum samples, venous blood was taken from patients and transferred to sterile test tubes. The blood was allowed to clot and was centrifuged for $5 \mathrm{~min}$ at $3000 \mathrm{rpm}$ [Figure 2]. The clear serum was separated and stored at $80^{\circ} \mathrm{C}$ until analysis [Figure 3]. For estimation of serum NO, method used by Jayasekharan et al., in 2014, was used. Serum samples were thawed to room temperature. $0.5 \mathrm{ml}$ of serum samples were taken and subjected for NO assay. To this, $0.5 \mathrm{ml}$ of Griess reagent was added. The content was mixed thoroughly. The reaction mixture was measured at $540 \mathrm{~nm}$ using microplate reader. Standard was prepared at various concentrations, which include $20 \mu \mathrm{g}, 40 \mu \mathrm{g}, 50 \mu \mathrm{g}$, and $60 \mu \mathrm{g}$. The average net optical density was calculated by subtracting the average value of sample (A1) from the average value of control (A0) and dividing with the average value of control (A0). Using the obtained absorbance value for each sample, the concentration of $\mathrm{NO}$ in serum samples was determined. $\mathrm{P}$ value between cases and control in serum samples of $\mathrm{NO}$ was statistically significant.

\begin{tabular}{lcc}
\multicolumn{3}{l}{ Table 1: Age and gender distribution in oral lichen planus } \\
Variables & Study group & Control group \\
\hline Male & $11(36.6 \%)$ & $9(30.0 \%)$ \\
Female & $19(63.3 \%)$ & $21(70.0 \%)$ \\
Age (years) & $34.45 \pm 10.47$ years $($ mean $\pm S D)$ \\
\hline
\end{tabular}

\begin{tabular}{lc} 
Table 2: Clinical types of OLP seen in the study patients \\
Clinical type of OLP & $\begin{array}{c}\text { Number of study } \\
\text { participants (\%) }\end{array}$ \\
\hline Reticular & $21(70.0)$ \\
Erythematous & $6(20.0)$ \\
Plaque & $2(6.6)$ \\
Ulcerative & $1(3.3)$ \\
\hline
\end{tabular}

OLP: Oral lichen planus

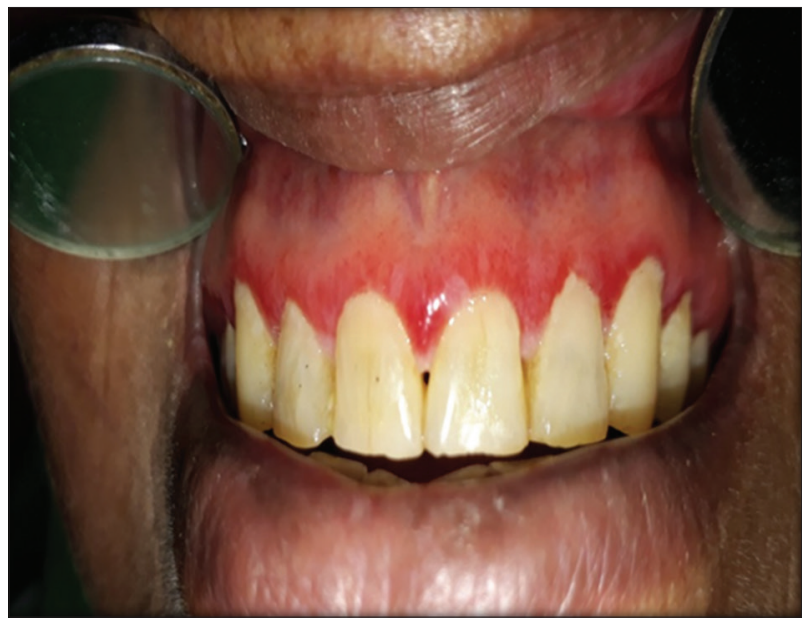

Figure 1: Clinical picture showing white striations interspersed with erythematous areas present on the maxillary anterior alveolar region

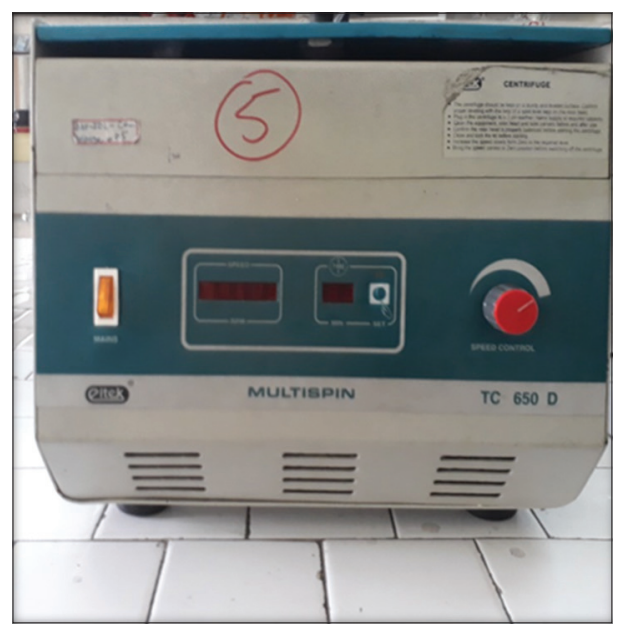

Figure 2: Centrifugation machine used in the present study

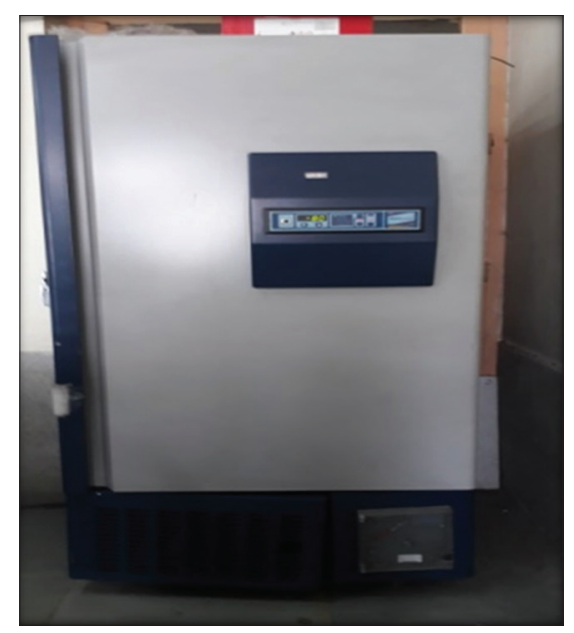

Figure 3: Serum samples stored at $-80^{\circ} \mathrm{C}$ 
Table 3: Nitric oxide assay in the study and control group

\begin{tabular}{llcc} 
Variable & Groups & Mean in serum $(\mu \mathbf{g} / \mathbf{m l})$ & $\boldsymbol{P}$ value \\
\hline Nitric oxide assay & Study group & 25.5 & 0.001 \\
& Control group & 11.7 & \\
\hline
\end{tabular}

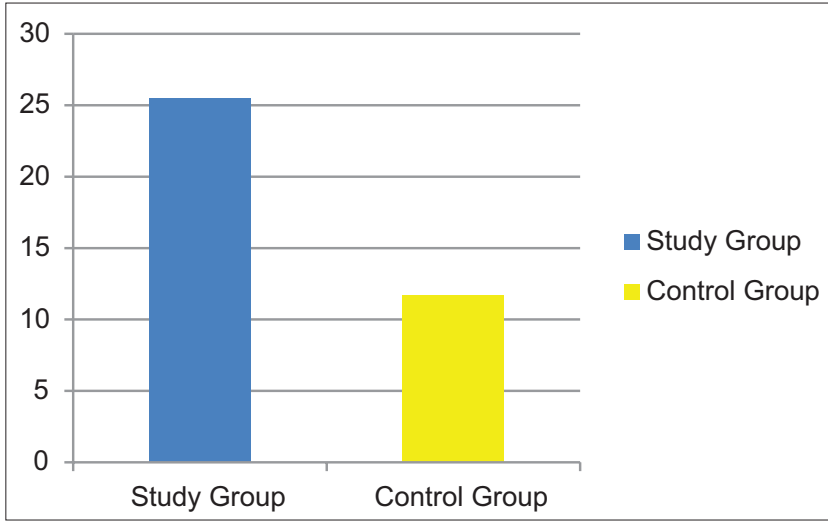

Graph 1: Nitric oxide assay in the study and control group

\section{Statistical Analysis}

Statistical analysis of the data was performed using the Statistical Package for the Social Sciences (SPSS Version 17) and inferences were drawn. Student's t-test was used to determine the statistical significance of serum NO levels within both patient and control groups. $P<0.05$ was considered statistically significant.

\section{RESULTS}

Of 30 patients included in the study group, 19 were female. In the control group, of 30 subjects, 21 were female. Age of the subject ranged from 34.45 \pm 10.47 years [Table 1]. The most common type of OLP seen was reticular type [Table 2].

The comparison between the control group and the lichen planus group in serum of NO assay group revealed that there is an increase in the mean value in lichen planus group. $P$ value between cases and control in serum samples of NO assay was $<0.001$ which was statistically significant [Table 3 and Graph 1].

\section{DISCUSSION}

$\mathrm{NO}$, a free radical gas, is a noxious chemical in the atmosphere but in small controlled concentrations in the body, acts as a physiological and pathophysiological mediator, and plays an important role in biological systems. There are two biological functions of NO. NO acts as an endothelial-derived relaxer of vascular smooth muscle, an inhibitor of platelet aggregation, and adhesion, and a neuronal messenger. Second, NO synthesized in large amounts by activated macrophage, it is well known that NO has damaging effects against cellular proteins, DNA, and lipids eventually leading to cell death, tissue injury, and organ failure. ${ }^{[9,10]}$

In the present study, the mean serum NO levels in patients with OLP were more than the control healthy individuals. According to Valko et al., serum NO has been found as a critical destructive mediator to the cell structures including lipids, proteins, and DNA which would clinically manifest as oral ulcers. ${ }^{[9]}$ This procedure justifies the formation of ulcer and erosion in the erosive lichen planus. Similar study conducted by Sunitha and Shanmugam supported the same. ${ }^{[9]}$

Mathews et al. found that in lichen planus, macrophages are frequently present in contact with lymphocytes displaying signs of activation and that they lie in close proximity to epithelial basal cells where cell damage occurs and have role in the pathogenesis of this condition. ${ }^{[11]}$

The enzyme inducible NO synthase (NOS) was originally described in macrophages. The inducible NOS once induced continue to produce NO for a much longer period than either neural or endothelial NOS. Inducible NOS readily observed in patients with infectious or inflammatory conditions; hence, NO could be increased in cellular infiltrate seen in OLP when compared with normal mucosa. ${ }^{[12,13]}$

Aly and Shahin reported an increase in the levels of NO in serum of patients with lichen planus and pointed to an increase in oxidative stress and an imbalance in the antioxidant defense mechanism in lichen planus. ${ }^{[14]}$ Investigations by Das et al. have indicated that free radicals including NO may play an important role in ulceration induced by several kinds of stress. ${ }^{[15]}$

\section{CONCLUSION}

Several studies have been done till date showing increased production of $\mathrm{NO}$ in serum and saliva sample in patient with OLP. NO is a free radicle, its increased production in the body 
shows increased oxidative stress in the patient. As seen in our study, levels of serum NO in OLP were significantly increased as compare to control. This shows that oxidative stress can be the possible etiologic factor for OLP and antioxidant may play a role in the treatment of the lesions. Till date, only symptomatic treatment is available for such cases which leaves patient debilitated. Antioxidants on long term may show promising results. This study was done on small sample size; further study with large sample size is advocated.

\section{REFERENCES}

1. Kurago ZB. Etiology and pathogenesis of oral lichen planus: An overview. Oral Surg Oral Med Oral Pathol Oral Radiol 2016;122:72-80.

2. Hassan I, Keen A, Majid S, Hassan T. Evaluation of the antioxidant status in patients of lichen planus in Kashmir valley a hospital based study. J Saudi Soc Dermatol Surg 2013;17:13-6.

3. Anshumalee N, Shashikanth MC, Sharma S. Oxidative stress and oral lichen planus: A possible association? Cusp 2007;4:31-4.

4. Valko M, Leibfritz D, Moncol J, Cronin MT, Mazur M, Telser J, et al. Free radicals and antioxidants in normal physiological functions and human disease. Int $\mathrm{J}$ Biochem Cell Biol 2007;39:44-84.

5. Omata N, Tsukahara H, Ito S, Ohshima Y, Yasutomi M, Yamada A, et al. Increased oxidative stress in childhood atopic dermatitis. Life Sci 2001;69:223-8.
6. Relhan V, Gupta SK, Dayal S, Pandey R, Lal H Blood thiols and malondialdehyde levels in psoriasis. J Dermatol 2002;29:399-403.

7. Yildirim M, Baysal V, Inaloz HS, Kesici D, Delibas N. The role of oxidants and antioxidants in generalized vitiligo. J Dermatol 2003;30:104-8.

8. Sezer E, Ozugurlu F, Ozyurt H, Sahin S, Etikan I. Lipid peroxidation and antioxidant status in lichen planus. Clin Exp Dermatol 2007;32:430-4

9. Sunitha M, Shanmugam S. Evaluation of salivary nitric oxide levels in oral mucosal diseases: A controlled clinical trial. Indian J Dent Res 2006;17:117-20.

10. Ormerod AD, Copeland P, Hay I, Husain A, Ewen SW. The inflammatory and cytotoxic effects of a nitric oxide releasing cream on normal skin. J Invest Dermatol 1999;113:392-7.

11. Matthews JB, Basu MK, Potts AJ. Macrophages in oral lichen planus. J Oral Pathol 1985;14:553-8.

12. Gandara BK, Izutsu KT, Truelove EL, Mandel ID, Sommers EE, Ensign WY, et al. Sialochemistry of whole, parotid, and labial minor gland saliva in patients with oral lichen planus. J Dent Res 1987;66:1619-22.

13. Whittle BJ. Nitric oxide in physiology and pathology. Histochem J 1995;27:727-37.

14. Aly DG, Shahin RS. Oxidative stress in lichen planus. Acta Dermatovenerol Alp Pannonica Adriat 2010;19:3-11.

15. Das D, Bandyopadhyay D, Bhattacharjee M, Banerjee RK Hydroxyl radical is the major causative factor in stressinduced gastric ulceration. Free Radic Biol Med 1997; 23:8-18. 